\title{
Posterior Fossa Dura Onarımında "iç Kapak" Yöntemi: Cerrahi Teknik ve Tek Merkezli Klinik Tecrübemiz
}

\author{
"Inner Flap" Method in the Reconstruction of Posterior Fossa Dura: Surgical Technique and Single Center Clinical \\ Experience
}

İhsan Doğan

Amaç: Posterior fossa cerrahisi sonrası hastalarda dura onarımındaki bașarısızlık beyin omurilik sızıntısına bağlı olarak kesi yeri iyileșmesine engel olabilmekte ve cerrahiye bağlı morbidite oranlarını artırabilmektedir. Bu çalıșmanın amacı, "iç kapak" yöntemi olarak isimlendirdiğimiz duraplasti ișlemini anlatmak ve bu yöntemi uyguladığımız hastaların klinik sonuçlarını, klasik dura tamiri yaptığımız hastaların sonuçlarıyla karșılaștırarak klinik tecrübemizi aktarmaktır.

Gereç ve Yöntem: Çalıșmaya posterior fossa patolojisi nedeniyle opere edilen ve duraplasti yapılan 30 hasta dahil edildi. Hastalar, klasik dura tamiri yapılan (Grup 1) ve duraları "iç kapak" yöntemiyle tamir edilen (Grup 2) grup olmak üzere iki grupta incelendi.

Bulgular: Klasik dura tamiri yapılan (Grup 1) hastaların 3' ünde beyin omurilik kaçağı izlenirken, iç kapak yöntemiyle dura onarımı yapılan (Grup 2) hastalarda izlenmedi. Tekniğimizi uyguladığımız gruptaki has taların hastanede ortalama kalıș süreleri diğer gruba göre 7 gün daha az olarak hesaplandı.

Sonuç: Tekniğimizin en büyük avantajı dura tamiri sırasında sütür iğnesine bağlı gelișen ufak deliklerin sağlam dura tarafından kapatılmasını sağlamasıdır. Tekniğimiz, uygulanabilirliği ve etkinliği açısından dura tamirinde güvenilir bir yöntemdir.

Anahtar Sözcükler: Posterior Fossa, Duraplasti, Yara Yeri lyileșmesi

Aim: Failure in reconstruction of dura in posterior fossa surgeries may result in cerebrospinal fluid leakage and thus hinder wound healing and increase surgical morbidity rate. The aim of this study was to describe a new duraplasty method termed as "inner flap" method and reporting our clinical experience by comparing the results of this method with other standard classical duraplasty procedures.

Material and Method: Thirty patients operated due to posterior fossa pathology were included in our study. These patients were divided into 2 groups whose duras were reconstructed by standard method (Group 1) and our technique "inner flap" (Group 2).

Results: In 3 patients whose duras were reconstructed by standard technique (Group 1), cerebrospinal leakage was observed while none of the patients in group 2 had any wound healing problems. Mean average hospital stay of patients in group 2 was calculated 7 days shorter than patients in group 1.

Conclusion: Most important advantage of our technique is that it provides closing minor holes due to suture needle by intact dura. Our technique is a safe method due to its effectivity and applicability.

Key Words: Posterior Fossa, Duraplasty, Wound Healing

Nöroşirurjikal girişimlerin her aşaması akılcıl planlamayı, doğru cerrahi teknik kullanımını, dikkatli ve özenli çalışmayı gerektirir. Kraniyal patolojilerin cerrahi tedavisini oluşturan tüm girișimsel basamakların herbirine aynı derecede önem verilmeli, cerrahinin "ciltten cilde" kesintisiz bir süreç ve bütün olduğu her zaman akılda tutulmalidır (1).

Iletișim

Uz. Dr. İhsan Doğan

E-mail: ihsandoganmd@gmail.com Tel: 03125082662

Fax: 03123106371

Ankara Üniversitesi Tıp Fakültesi Beyin ve Sinir Cerrahis

Anabilim Dalı ibni Sina Hastanesi 7.Kat 06100

Sihhiye/ Ankara
Kaldırılan kemiğin ve açılan duranın uygun ölçülerde olması patolojiye ulaşım ve güvenli bir cerrahi için hayati öneme sahiptir (2,3). Aynı şekilde, bu işlemler sirasinda dura bütünlüğünün korunması ve patolojiye yönelik cerrahi işlemin tamamlanmasını takiben duranın anatomik planda su geçirmez bir şekilde onarılması, cilt ve cilt altı dokuların beyin omurilik sıvısı (BOS) ile temasını engelleyecek şekilde kapatılması yarayeri iyileşmesini sağlamakta, sonuç olarak da hastaların ameliyat sonrası yaşam kalitelerini de olumlu yönde etkilemektedir $(4,5)$ 